\title{
Detection of Precipitation and Temperature Trend Patterns for Mulanje District, Southern Part of Malawi
}

\section{Kachaje $\mathbf{O}^{1^{\star}}$, Kasulo $\mathbf{V}^{2}$ and Chavula $\mathbf{G}^{1}$}

${ }^{1}$ University of Malawi-Polytechnic, Chichiri, Blantyre, Malawi

${ }^{2}$ Mzuzu University, Mzuzu, Malawi

*Corresponding author: Kachaje O, University of Malawi-Polytechnic, P/Bag 303, Chichiri, Blantyre 3, Malawi, Tel: +265 1870411 ; E-mail: okachaje@gmail.com

Received date: Nov 08, 2016; Accepted date: Dec 13, 2016; Published date: Dec 26, 2016

Copyright: (C) 2016 Kachaje O, et al. This is an open-access article distributed under the terms of the Creative Commons Attribution License, which permits unrestricted use, distribution, and reproduction in any medium, provided the original author and source are credited.

\begin{abstract}
This paper reports on the recent trend of climate changes taking place in Mulanje, one of the major tea producing districts in Malawi, with a focus on precipitation and temperature. The study analyzed trends in weather time series (air temperature and rainfall) data from 1980 to 2011 using non-parametric Mann-Kendall test. The MK test gave a mix of positive and negative trends for the monthly and seasonal precipitation. Only the month of December showed a positive significant trend while February, April, May, June September, October and November had a significant negative trend. Cool and wet as well as hot and dry season showed a significant decreasing trend in precipitation. The data also indicated that annual rainfall variation is decreasing with time at the rate of about $4.29 \mathrm{~mm}$ per year while temperature is increasing by about $0.04^{\circ} \mathrm{C}$ every year. The MK test for temperature results showed a significant increasing trend for both mean annual minimum and maximum temperature. The results of the study do not deny climate change is happening, therefore, proper adaptation measures should be employed to reduce the vulnerability to climate change in the area because of its economic significance in tea production.
\end{abstract}

Keywords: Climate change; Malawi; Precipitation; Temperature; Mann-Kendall

\section{Introduction}

There is a worldwide consensus that climate change is a real, rapidly advancing and widespread threat [1]. The change in climate will result in alteration of temperature and rainfall regimes in most regions of the world. While climate change results from activities all over the globe with rather unevenly spread contributions to it, Africa at large and southern Africa in particular will be the most affected part of the world due to lack of adaptation and mitigating measures [2].

Climate change will lead to very different impacts in different countries, depending on local, regional environmental conditions and on differences in vulnerability to climate change [3].

Malawi as a country has experienced extreme weather events over the last few decades, ranging from droughts (1991/92) to floods (1996/97) and flush floods (2000/01). These extreme weather events also affects the country differently since its climate is significantly moderated by the effects of Lake Malawi, high altitudes and proximity to the influence of westerly frontal systems which move eastwards around the South African coast, influencing the temperatures to be relatively cool [4].

The country's climate has two distract seasons, the rainy season from November to April and the dry season from May to October. However, the dry season is subdivided into two parts namely cool and wet (May to August) and hot and dry (September to October).

Detailed rainfall climatology for Malawi by Nicholson et al. [5] revealed that the rainfall regime in 75 weather stations throughout Malawi is not homogeneous. Through correlating the stations from one another, the country was divided into four regions by combining the stations as illustrated in Figure 1. A major implication of the results was that the factors governing inter-annual variability may be quite different for the early and late rainy seasons and global climate change might affect these regions differently.

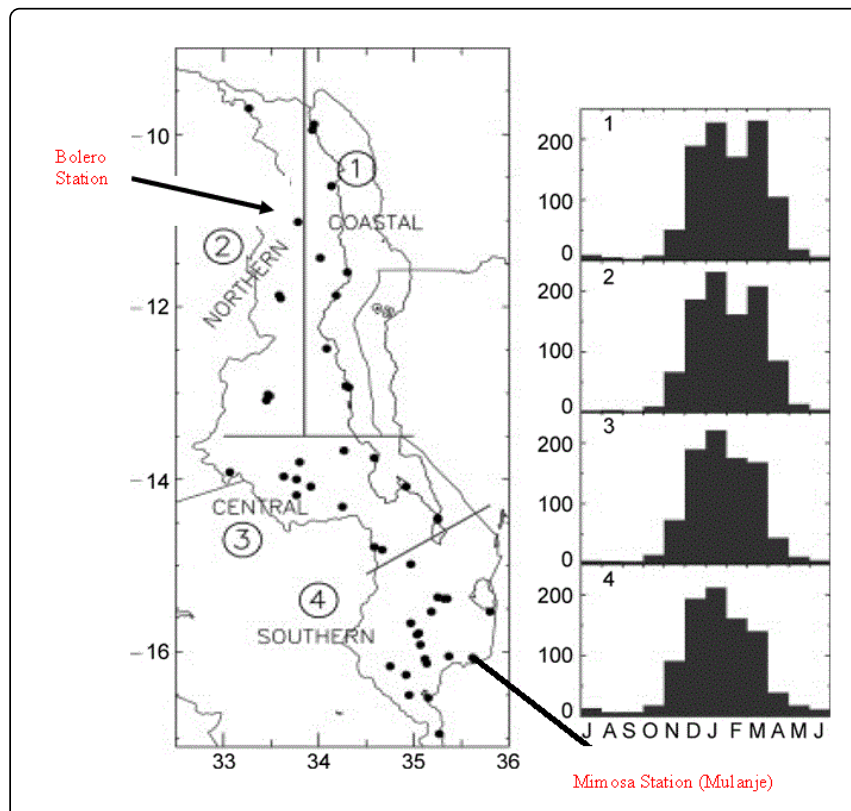

Figure 1: Left: homogeneous rainfall regions of Malawi and the stations within them. Right: The typical seasonal cycle of rainfall (mm per month) in each [5]. 
In the quest of forecasting climate change pattern for Bolero Agriculture Extension Planning Area in Malawi, Singini et al. [6] concluded that the maximum temperature has increased by $1.6^{\circ} \mathrm{C}$ from $27.7^{\circ} \mathrm{C}$ in 1982 and will increase to $29.3^{\circ} \mathrm{C}$ in 2030 . This increase in temperature would have a negative impact on agricultural livelihood options in the area (Bolero). The geographic position of Bolero falls in region 2 (Figure 1), and as attested by Nicholson et al. [5], the regions are not homogeneous and thus the climate for region 2 is different from other regions. Therefore, this calls for reasons to investigate the change in climate for Mulanje district (in region 4) in order to reveal the impact it will have on the people in the district.

Mulanje District is named after the highest Mountain in the SouthCentral Africa and is located approximately $65 \mathrm{~km}$ east of Blantyre district (Figure 2). The district local weather conditions are greatly influenced by the Mulanje Mountain, the southern portion of the eastern Shire Highlands, and the climate is also partly affected by Chiperoni winds causing high rainfall on the windward (South East side of the Mulanje Mountain) while limiting it on the leeward side [7]. The average annual rainfall is $1600 \mathrm{~mm}$ and the average minimum annual temperatures ranges from $21^{\circ} \mathrm{C}$ to $23^{\circ} \mathrm{C}$ and the maximum temperatures of about $32^{\circ} \mathrm{C}$ to $35^{\circ} \mathrm{C}$ [8]. Taulo et al. [7] also note that one most distinctive feature of Mulanje climate is the variation of rainfall over short distances, a characteristic attributed to the influence of Mulanje Mountain.

The aim of this study was to analyse the recent trend of climate changes taking place in the area (Mulanje), with a focus on precipitation and temperature. The district was chosen due to the economic significance it contributes to the growth of the nation. Malawi as a country heavily depends on agricultural products as its main exports. Apart from tobacco, sugar and coffee, tea is one of Malawi's top main exports and accounts for $8 \%$ of the export earnings [9]. Mulanje is one of the major districts where the crop is grown because its soils, climatic conditions and sloping ground of the area around Mount Mulanje are well suited to the crop [10]. However, prolonged droughts, increased temperatures, late onset and early cessation of precipitation will affect tea production [11]. Climate change could therefore negatively affect the tea industry of Mulanje district and later on Malawi. The results of the study are to inform practitioners, policy makers and the community on the future projections of climate change in the district, its effects and strategies for adaptation.

\section{Materials and Methods}

\section{Data and methods}

To assess the recent trend patterns in Mulanje district, we collected the historic temperature and precipitation data for the district. The utilized data in these studies was kindly provided by the Department of Climate Change and Meteorological Services (DCCMS). Pre-quality analyses of the data were done by DCCMS. The mean monthly minimum temperature and mean monthly maximum temperature data as well as the monthly and seasonal precipitation for the past 31 years (1980 to 2011) from Mimosa station was analysed to infer for any changes in climate. The data was logically interpreted along with simple tables, charts and graphs.

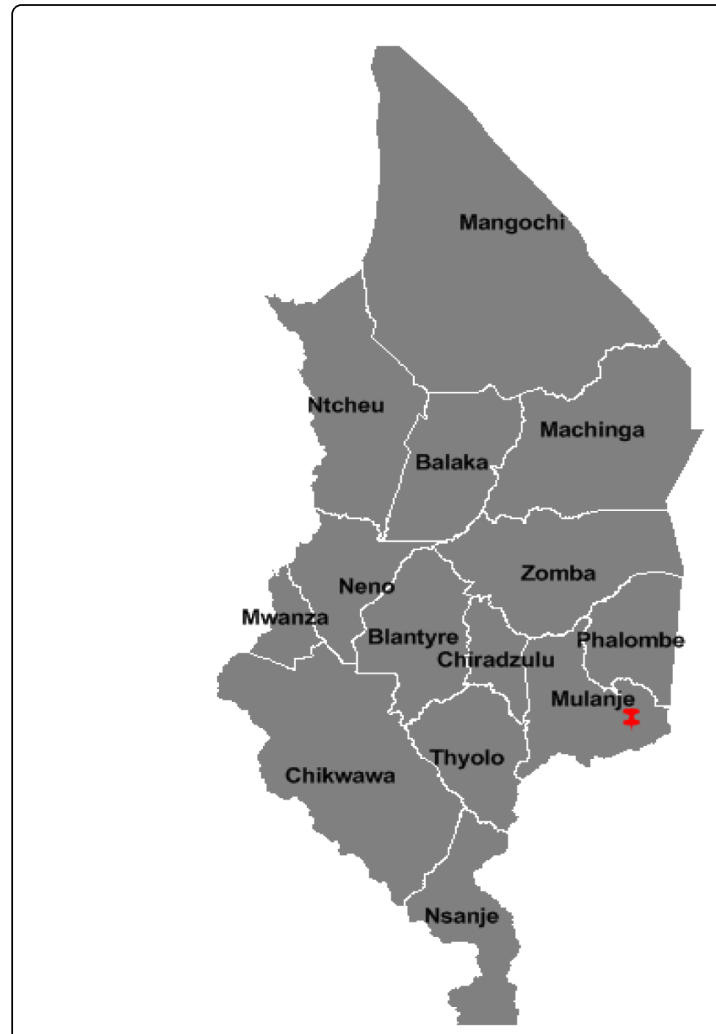

Figure 2: Map of southern Malawi showing study location.

\section{Data analysis}

The precipitation and temperature data were used to analyze the changes in trend happening in Mulanje district over the years. XLSTAT 2016 was used for Mann-Kendall (MK) statistical test to detect if any statistically significant trends exist in the data. This test, MK, is a powerful non-parametric method tool for analyzing long time series data such as precipitation, temperature and discharge. Under the null hypothesis (H0), the assumption is that there is no trend in the data and the alternative hypothesis ( $\mathrm{H} 1)$ carries the assumption that there is an increasing or decreasing trend over time. The mathematical computational for the MK test statistics S, Var (S) and the standard test statistic ZS were calculated as follows:

$$
S=\sum_{i=1}^{n=1} \sum_{j=i+1}^{n} \operatorname{sign}(T j-T i)
$$

$\operatorname{sign}(T j=T i)=\left\{\begin{array}{l}1 \quad \text { if } T j-T i>0 \\ 0 \quad \text { if } T j-T i=0 \\ -1 \text { if } T j-T i<0\end{array}\right.$

$$
\sigma^{2}=\frac{n(n-1)(2 n+5)-\sum t_{i}(i)(i-1)(2 i+5)}{18}
$$


Citation: Kachaje O, Kasulo V, Chavula G (2016) Detection of Precipitation and Temperature Trend Patterns for Mulanje District, Southern Part of Malawi. J Climatol Weather Forecasting 4: 187. doi:10.4172/2332-2594.1000187

Page 3 of 6

$$
Z_{s}= \begin{cases}\frac{s-1}{\sigma} & \text { for } S>0 \\ 0 & \text { for } S=0 \\ \frac{s+1}{\sigma} & \text { for } S<0\end{cases}
$$

where $\mathrm{Tj}$ and $\mathrm{Ti}$ are the actual time series observation data, $\mathrm{n}$ is the period of the time series data, ti denotes the number of ties up to sample i. The test statistic ZS follows normal distribution and was used as a measure of significance of trend. Positive and negative values of ZS signify an increase and decreasing trend respectively. A significance level $\alpha$ is used to test the null hypothesis (increase or decreasing) trend exist. If $\mathrm{ZS}$ is greater than $\mathrm{Za} / 2$, the null hypothesis is rejected implying that the trend is statistically significant. The chosen significance level for this study was 1.96 for $\mathrm{p}$-value of 0.05 . However, before running a MK trend test, autocorrelation was considered to remove the serial dependence of the time series data that would cause problems in testing of data and interpretation of results, according to the method proposed by Yue and Wang [12].

\section{Results and Discussion}

\section{Precipitation}

Rainfall distribution: The 31 years' data of monthly and seasonal rainfall from 1980 to 2011 at Mimosa station in Mulanje district was analyzed for changes in rainfall distribution, and results of the analysis are given in Figure 3. The results showed that about $85 \%$ of the rainfall occurs during rainy season (November to April), 10\% during the cool and wet season (May to August) and finally, 5\% during the hot and dry season (September to October).

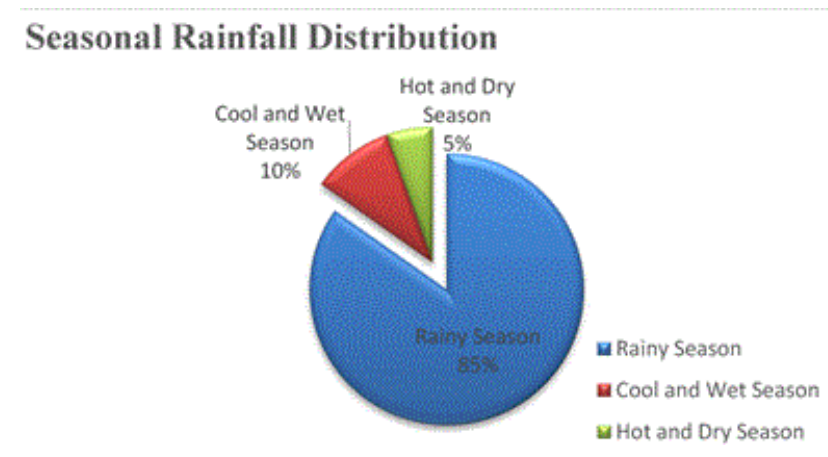

Figure 3: Seasonal rainfall distribution in Mulanje.

The mean daily rainfall distribution in Mulanje district for the same period (1980 to 2011) is shown in Figure 4, and shows that precipitation in Mulanje starts from the $295^{\text {th }}$ day, which is in October, and is highest between about the $341^{\text {th }}$ to $65^{\text {th }}$ days in the year, which is the period during November to March (rainy season in Malawi). These results are in agreement with most of the studies done on Malawi about the onset, duration and end of rainy season, that is, it begins in October or November and continues until March or April [4,5,13-18].

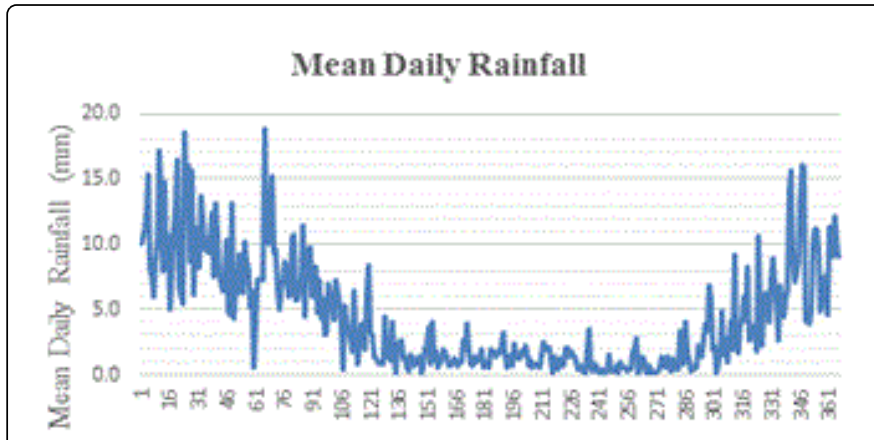

Figure 4: Daily rainfall distribution in Mulanje.

\section{Annual rainfall variation}

The average annual rainfall data for period 1980 to 2011 (31 years) used in this study showed that the average annual rainfall of Mulanje is decreasing at a rate of about $4.29 \mathrm{~mm}$ per year (Figure 5). This is in agreement with the observation [16] which shows a general decrease in the mean monthly rainfall with time. From this analysis, the maximum occurrence of rainfall occurred in 1988/89 season and the minimum rainfall occurred in 1991/92 season with total annual precipitation of $2356.5 \mathrm{~mm}$ and $811.2 \mathrm{~mm}$ respectively. It was these years, 1991/92, when Malawi experienced severe drought across all regions of the country. It was also observed from the results that the average rainfall is $1631.1 \mathrm{~mm}$ for the 31 year period representing an average of about $135.9 \mathrm{~mm}$ of precipitation per month [17].

However, Vincent [18] reports that the amount of rainfall in southern Malawi is between $150 \mathrm{~mm}$ and $300 \mathrm{~mm}$ per month and hence that for Mulanje is below this range. Bulckens [19] also observed a decrease in rainfall in Mulanje district from an average of $2000 \mathrm{~mm}$ in 1960 to about $1500 \mathrm{~mm}$ in 2012 . This clearly shows that there is a decline in annual rainfall distribution for period 1980 to 2011 and more analysis needs to be done to see whether this trend will continue.

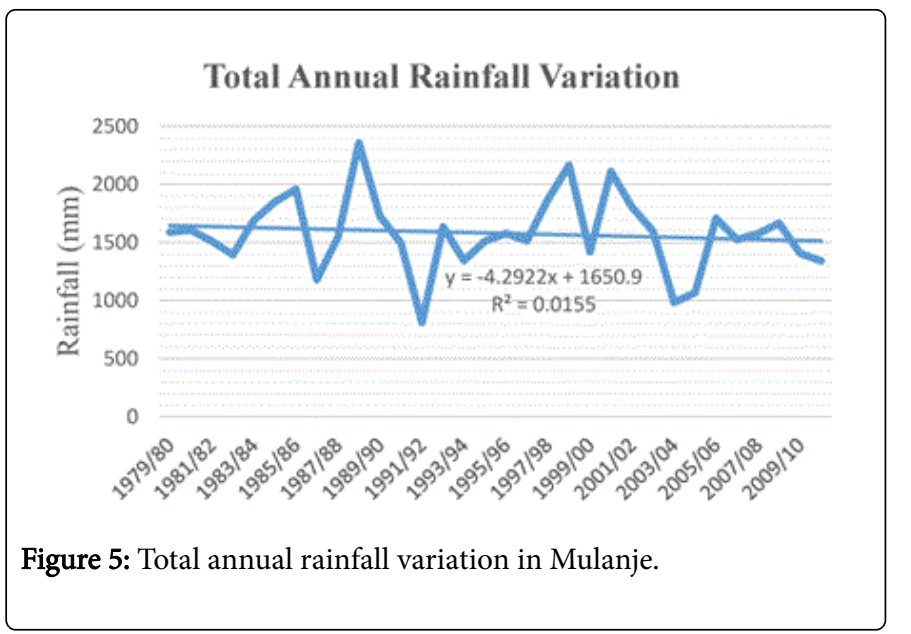



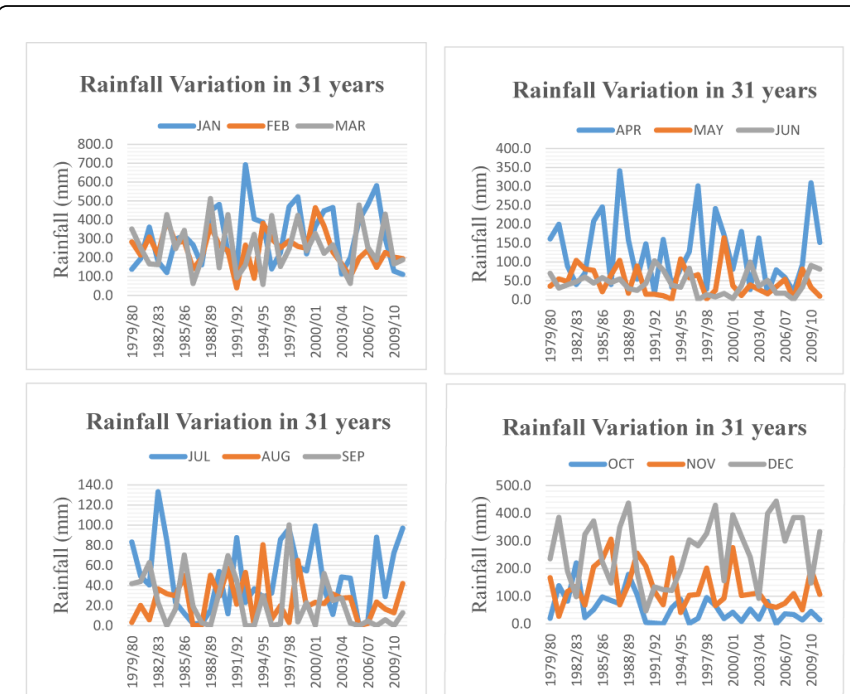

Figure 6 shows the rainfall variation for individual months for the 31 years period. It was observed that the minimum average annual rainfall occurs in the month of September $(23.6 \mathrm{~mm})$ followed by August $(26.2 \mathrm{~mm})$ and the maximum average rainfall is in January $(322 \mathrm{~mm})$ and December $(274.3 \mathrm{~mm})$.

In order to detect if the trends in the precipitation were significant, the MK test was applied on a monthly scale for the entire period from 1980 to 2011 (31 years). The summary results of non-parametric MK test for trend analysis of data are presented in Table 1 . The results for monthly trend tests showed a mix of positive and negative trends with January, July and December depicting a positive trend and the rest of the months of the year showing negative trend. The increasing trend in precipitation for December was statistically significant $(p=0.006)$. Significant negative trend were detected in the months of February, April, May, June September, October and November; no significant trends were found for the other months. The significant decrease of precipitation in October and November confirms the observation by many studies that the rains are shifting towards December $[13,15,17]$.

Figure 6: Rainfall variations for individual month for 31 years.

\begin{tabular}{|c|c|c|c|c|c|c|c|}
\hline Variable & Kendalls tau & s & $\operatorname{Var}(\mathbf{S})$ & $\begin{array}{l}\begin{array}{l}\text { P-value } \\
\text { tailed) }\end{array} \quad \text { (Two- } \\
\end{array}$ & Alpha & Interpretation & Trend \\
\hline JUL & 0.06 & 31 & 792.5 & 0.287 & 0.05 & Accept & NST \\
\hline AUG & -0.03 & -13 & 646.9 & 0.637 & 0.05 & Accept & NST \\
\hline SEP & -0.22 & -104 & 428.5 & $<0.0001$ & 0.05 & Reject & Decreasing \\
\hline OCT & -0.29 & -145 & 634.4 & $<0.0001$ & 0.05 & Reject & Decreasing \\
\hline NOV & -0.16 & -78 & 720.9 & 0.004 & 0.05 & Reject & Decreasing \\
\hline DEC & 0.15 & 73 & 681.6 & 0.006 & 0.05 & Reject & Increasing \\
\hline JAN & 0.1 & 52 & 770.7 & 0.066 & 0.05 & Accept & NST \\
\hline FEB & -0.22 & -108 & 692.6 & $<0.0001$ & 0.05 & Accept & Decreasing \\
\hline MAR & -0.03 & -16 & 137.4 & 0.201 & 0.05 & Accept & NST \\
\hline APR & -0.1 & -49 & 299 & 0.006 & 0.05 & Reject & Decreasing \\
\hline MAY & -0.21 & -104 & 257.2 & $<0.0001$ & 0.05 & Reject & Decreasing \\
\hline JUN & -0.15 & -75 & 678.6 & 0.005 & 0.05 & Reject & Decreasing \\
\hline
\end{tabular}

Table 1: MK tests results for precipitation in monthly time series. NST: NoSignificant Trend.

\section{Seasonal rainfall variation}

The hot and dry season precedes the rainy season. Rainfall data for about 61 days from September to October was analysed. The hot and dry season average annual rainfall variation together with the nonrainy days in Mulanje results are shown in Figure 7. The observation was that the season annual rainfall is decreasing by about $3.52 \mathrm{~mm}$ per year in the district. The UNDP climate change profile on Malawi done by McSweeney et al. [20] also showed that the projections in rainfall tend to decrease in September, October and November. The number of non-rainy days, as depicted in Figure 7, is increasing within the season. Historically, the rains in most parts of the country were beginning in late October $[4,16]$. This may also explain the changes in the onset of rainy season, as many studies have attested it is shifting towards December and making agricultural decisions regarding planting more difficult and less reliable $[13,15,17]$.

The average annual rainfall distribution and non-rainy days during the rainy season (November to April) were also analysed as shown in Figure 7 . It was observed that the rainy season average annual rainfall showed a mild increase in trend of about $0.63 \mathrm{~mm}$ per year. This was also attested by McSweeney et al. [20] where rainfall projections over Malawi showed an increasing trend during the rainy season. The slope of the trend line for number of non-rainy days during the season is not very large in magnitude but it is positive indicating a small increase. Hence, the amount of rainfall being received in the district is almost 
Citation: Kachaje O, Kasulo V, Chavula G (2016) Detection of Precipitation and Temperature Trend Patterns for Mulanje District, Southern Part of Malawi. J Climatol Weather Forecasting 4: 187. doi:10.4172/2332-2594.1000187

Page 5 of 6

the same every season of the year but in lesser number of days. The Participatory Rural Assessment (PRA) exercise reported that villagers are experiencing late onset of the rains and an earlier cessation from what they consider "normal rainy seasonal" [13,15,17]. Generally, projections for Malawi as a whole are mainly consistent which suggest a later onset of rainy season and shows an enhancement of rainfall during the months of December through February, followed by an early cessation $[4,5,16,17,20]$.

Similar to hot and dry season, the trend of the cool and wet season (May to August) average seasonal rainfall is decreasing by about 1.4 $\mathrm{mm}$ per year, with an increasing number of non-rainy days are also increasing as shown in Figure 7. Rainfall projections for the austral winter months (June, July and August) tend to decrease June to August becoming exceedingly dry over most of Malawi, with seasonal rainfall in the order of $10 \mathrm{~mm}$ to $25 \mathrm{~mm}[5,20]$. These trends, therefore, needs to be analyzed further to evaluate if the changes are significant in the district in seasonal time series.

Hence, the MK test was also used to detect trends in seasonal precipitation between 1980 and 2011 period and the results are given in Table 2. Similar to the monthly analysis, results from ZS statistics shows a mix of negate and positive trends. Cool and wet as well as hot and dry season showed a decreasing negative trend in precipitation and trends were statistically significant implying that the precipitation in these two seasons is decreasing over time. However, thought not statistically significant, a positive precipitation trend was detected for rainy season.
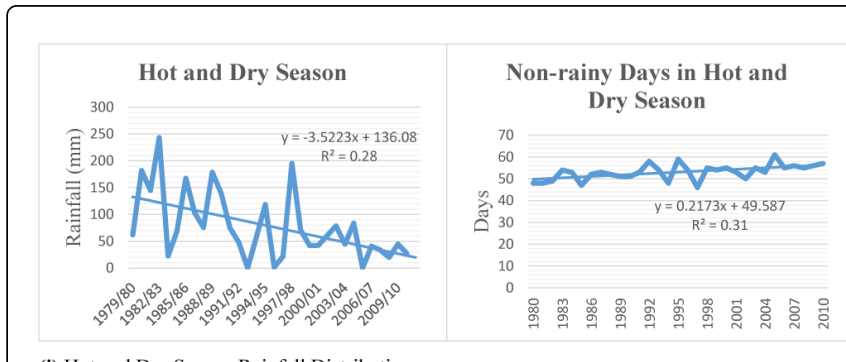

(i) Hot and Dry Season Rainfall Distribution
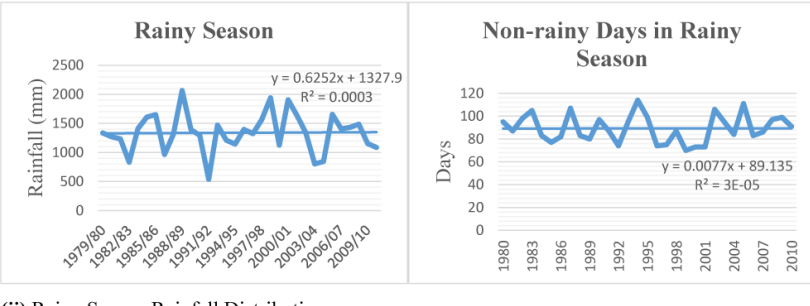

(ii) Rainy Season Rainfall Distribution

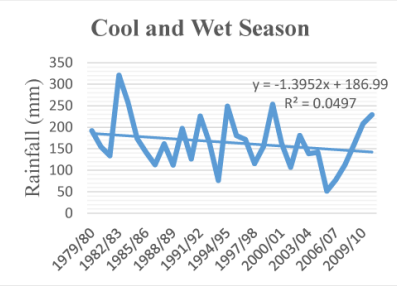

(iii) Cool and Wet Season Rainfall Distribution

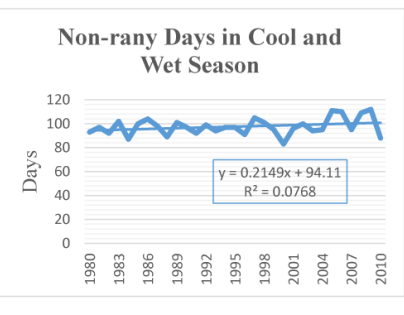

Figure 7: Seasonal rainfall distribution.

\begin{tabular}{|l|l|l|l|l|l|l|l|}
\hline Variable & Kendalls tau & $\mathbf{S}$ & Var (S) & P-value (Two-tailed) & Alpha & Interpretation & Trend \\
\hline Rainy & 0.03 & 16 & 391.2 & 0.448 & 0.05 & Accept & NST \\
\hline Cool \& Wet & -0.12 & -60 & 465.8 & 0.006 & 0.05 & Reject & Decreasing \\
\hline Hot \& Dry & -0.3 & -150 & 473.5 & $<0.0001$ & 0.05 & Reject & Decreasing \\
\hline
\end{tabular}

Table 2: MK tests results for precipitation in seasonal time series. NS: No Significant Trend.

\section{Temperature}

The temperature data from 1980 to 2010 was also analyzed. Figure 8 shows that both mean annual minimum temperature and mean annual maximum temperature for Mulanje is increasing by about $0.04^{\circ} \mathrm{C}$ every year. Phiri and Saka [21] also observed that mean temperatures in the lower Shire (Chikwawa and Nsanje districts) had increased by $2.3 \%$ while mean maximum temperatures had increased by $2 \%$ between 1970 and 2002. Meanwhile, for the period 1960 to 2006 [20], observed that mean annual temperature increased by $0.9^{\circ} \mathrm{C}$, an average of $0.21^{\circ} \mathrm{C}$ per decade. The observation from the temperature analysis done here shows consistency with the GCMs which is in also in conformity with temperature projections for the whole country. This increase in temperature has also been perceived by villagers in a PRA study $[15,17]$ and the results highlighted warming temperatures as one of the most visible impacts of climate change in Malawi.
On running the MK test on mean monthly and mean maximum temperature data to detect if there was a trend in the 30 years period, the following results in Table 3 were obtained.
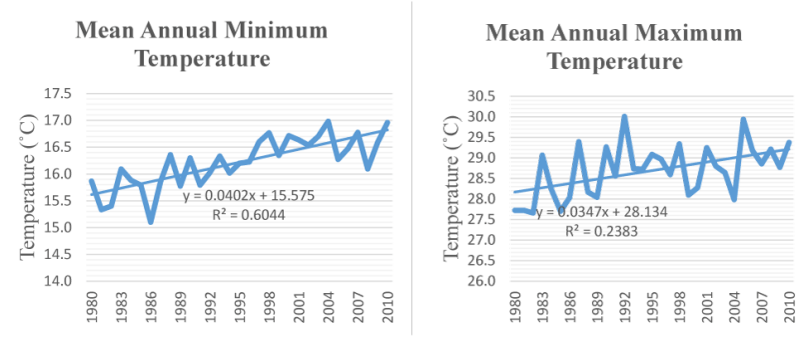

Figure 8: Annual mean minimum and maximum temperature. 
Page 6 of 6

The results indicated that there was significant increasing trend for both mean annual minimum and maximum temperature. Therefore, further impacts associated with the increasing temperature in Mulanje district should be looked upon.

\begin{tabular}{|l|l|l|l|l|l|l|}
\hline Variable & Kendall's tau & $\mathbf{S}$ & Var(S) & $\begin{array}{l}\text { p-value (Two- } \\
\text { tailed) }\end{array}$ & alpha & Interpretation \\
\hline Mean annual minimum temperature & 0.58 & 268 & 651.9 & $<0.0001$ & 0.05 & Reject \\
\hline Mean annual maximum temperature & 0.34 & 158 & 912.3 & $<0.0001$ & 0.05 & Reject \\
\hline
\end{tabular}

Table 3: MK tests results for temperature in annual time series.

\section{Conclusion}

The evidence from this paper shows that there are some changes in the trend of temperature and precipitation of the district in the 31 years' period analyzed in different months. The data indicated that the annual rainfall variation is decreasing with time at the rate of about $4.29 \mathrm{~mm}$ per year. It also showed that the rainy season is shortening; however, the amount of rainfall being received is almost the same every season but in lesser number of days. The MK test gave a mix of positive and negative trends for the monthly and seasonal precipitation. Only the month of December showed a positive significant trend while February, April, May, June September, October and November had a significant negative trend. Cool and wet as well as hot and dry season showed a decreasing negative trend in precipitation and trends were statistically significant. However, thought not statistically significant, a positive precipitation trend was detected for rainy season. Similarly, temperature has been and can be predicted to be rising in the years to come (by about $0.04^{\circ} \mathrm{C}$ every year) which can lead to high evapotranspiration hence less discharge. On running the MK test for temperature, the results indicate that there is significant increasing trend for both mean monthly and mean maximum temperature. Therefore, the results of the study do not deny climate change is happening and calls for further study on climate change in the district and their impacts on tea production.

\section{Acknowledgement}

The work towards this study was financed by the Scottish government through the University of Stathclyde and University of Malawi-Polytechnic.

\section{References}

1. Mishra BK, Herath S (2012) An investigation on climate change risk for run-of-river hydropower schemes: a case study of Sunkoshi river basin, Nepal.

2. IPCC (2001) Climate Change 2001, Impacts, adaptation and vulnerability. Contribution of Working Group II, Cambridge, Cambridge University Press for Intergovernmental Panel on Climate Change.

3. United Nations Environmental Program/Earths can (UNEP/Earthscan) (2002) Global Environmental Outlook 3. London: Earthscan.
4. Ministry of Natural Resources and Environmental Affairs (MoNRE) (2002) Initial National Communication to the Conferences of Parties of the United Nation Framework Convention on Climate Change.

5. Nicholson SE, Klotter D, Chavula G (2013) A detailed rainfall climatology for Malawi, Southern Africa. Int J Climatol 34: 315-325.

6. Singini W, Tembo M, Banda C (2015) Forecasting Climate Change Pattern for Bolero Agriculture Extension Planning Area in Malawi. J Climatol Weather Forecasting 3: 145.

7. Taulo JL, Mkandawire RW, Gondwe KJ (2008) Energy policy research baseline for Mulanje and Phalombe districts.

8. Haarstad J, Jumbe CBL, Chinangwa S, Mponela P, Dalfelt A, et al. (2009) Environmental and Socio-Economic Baseline Study - Malawi. Norwegian Agency for Development Cooperation.

9. Fairtrade foundation (2010) Fairtrade Tea: Early Impacts in Malawi.

10. IRIN (2011) Tea tells the future of the climate.

11. Food and Agriculture Organization (FAO) (2014) Intergovernmental Group on Tea, Report of the Working Group on Climate Change-21st Session.

12. Yue S, Wang C (2004) The Mann-Kendall test modified by effective sample size to detect trend in serially correlated hydrological series. Water Resour Manag 18: 201-218.

13. ActionAid (2006) Climate change and smallholder farmers in Malawi: Understanding poor people's experiences in climate change adaptation.

14. Kaunda CS, Mtalo F (2013) Impacts of environmental degradation and climate change on electricity generation in Malawi. Int J Energ Env 4: 481- 496.

15. Magrath J, Sukali E (2009) The winds of change: Climate change, poverty and the environment in Malawi, Oxfam International.

16. Ministry of Natural Resources and Environmental Affairs (MoNRE) (2011) Second National Communication to the Conferences of Parties of the United Nation Framework Convention on Climate Change.

17. USAID (2013) Malawi Climate Change Vulnerability Assessment.

18. Vincent K, Dougill AJ, Mkwambisi DD, Cull T, Stringer LC, et al. (2014) Analysis of Existing Weather and Climate Information for Malawi.

19. Bulckens H (2013) Helping Smallholder Tea Farmers, Malawi. Ethical Tea Partnership.

20. McSweeney C, New M, Lizcano G (2011) UNDP Climate Change Country Profiles: Malawi.

21. Phiri MGI, Saka AR (2004) The impact of changing environmental conditions on vulnerable communities of the Shire valley, southern Malawi. 